\title{
First report of Colletotrichum theobromicola causing anthracnose on Anthurium sp.
}

\author{
Tamires Paixão Chaves ${ }^{1}$. Ana Raphaela Gomes Silva Miranda ${ }^{1}$ • Luan Carlos da Paz ${ }^{1}$ (i) • Mariote Santos Brito Netto ${ }^{1}$. \\ Gaus Silvestre Aandrade Lima ${ }^{1}$ - Iraildes Pereira Assunção ${ }^{1}$
}

Received: 22 May 2019 / Accepted: 29 May 2020 / Published online: 2 July 2020

(C) Australasian Plant Pathology Society Inc. 2020

\begin{abstract}
Anthurium is one of the most frequently grown commercial tropical flowers. In December 2016, Anthurium flowers with circular necrotic spot symptoms were collected in Brazil. Based on morphological and molecular characterisation, the fungus isolates were identified as Colletotrichum theobromicola, which were detected for the first time causing anthracnose on Anthurium in the world.
\end{abstract}

Keywords Tropical flowers $\cdot$ Araceae $\cdot$ Fungal disease $\cdot$ Phylogenetic analysis

The Araceae are widely distributed in Brazil, with species occurring from the southern most subtropical areas to the equatorial rainforest in the extreme north of the country. The genus Anthurium contains 130 native species from Brazil, which are known most commonly as anthurium, flamingo flower and tailflower (Tombolato and Castro 2005). Colletotrichum species are among the most important damaging pathogens infecting economic crops such as vegetables, fruits, flowers and non-cultivated plants. Tropical flowers are expected to have a good appearance, however disease damage affects marketability. In Brazil, information about tropical flower diseases is limited (Figs. 1, 2, 3 and 4).

In December 2016, flowers (Anthurium spp.) with circular necrotic spot symptoms were collected in Atalaia, state of Alagoas, Brazil. Initially, small symptomatic flower pieces were cut from the edge of the diseased and healthy sections and were surface sterilised with $70 \%$ ethanol for $30 \mathrm{~s}$ and $1 \% \mathrm{NaOCl}$ for 1 min followed by two washes in sterile distilled water, then placed on

Luan Carlos da Paz

luancpaz@hotmail.com

Setor de Fitossanidade/Centro de Ciências Agrárias, Universidade Federal de Alagoas, Rio Largo, AL 57100-000, Brazil
$2 \%$ water agar $(w / v)$, and incubated at $25^{\circ} \mathrm{C}$ for 5 days. Hyphae extending from the flower pieces were transferred to potato dextrose agar (PDA). After incubation at $25{ }^{\circ} \mathrm{C}$ for 7 days under $12 \mathrm{~h}$ light-dark cycles, initial identification of the isolates was realised according to Sutton (1992). Six Colletotrichum-like isolates were obtained by single-spore culture in potato dextrose agar (PDA) and deposited in the Culture Collection Micoteca URM at the Universidade Federal de Pernambuco (URM8227). The isolates produced white cottony aerial hyphae that later became brown. The underside of the colony was uniformly black with a growth rate of $44 \mathrm{~mm} / \mathrm{day}$. Conidia hyaline, straight to cylindrical, aseptate and 7.5 to 25.5 (15.5) $\mu \mathrm{m}$ and 3.5 to 6.5 (4.5) $\mu \mathrm{m}$. The morphological characteristics were consistent with the descriptions of species in the Colletotrichum gloeosporioides species complex.

To confirm the identity of the isolates, partial sequences of the internal transcribed spacer (ITS) of rDNA region, glyceraldehyde-3-phosphate dehydrogenase (GAPDH), calmodulin (CAL), chitin synthase (CHS) and actin (ACT) genes were amplified. The reaction mixture and cycling conditions were the same as described by Carbone and Kohn (1999) and Weir et al. (2012). The sequences of URM8227, as a representative isolate, were submitted to GenBank (MH155178, 
Fig. 1 Lesions, circular necrotic spots on petals caused by C. theobromicola in Anthurium flowers (a) Symptoms on flowers of Anthurium with injury 3 days post inoculation; (b) Symptoms observed in pathogenicity tests no injury 3 days post inoculation

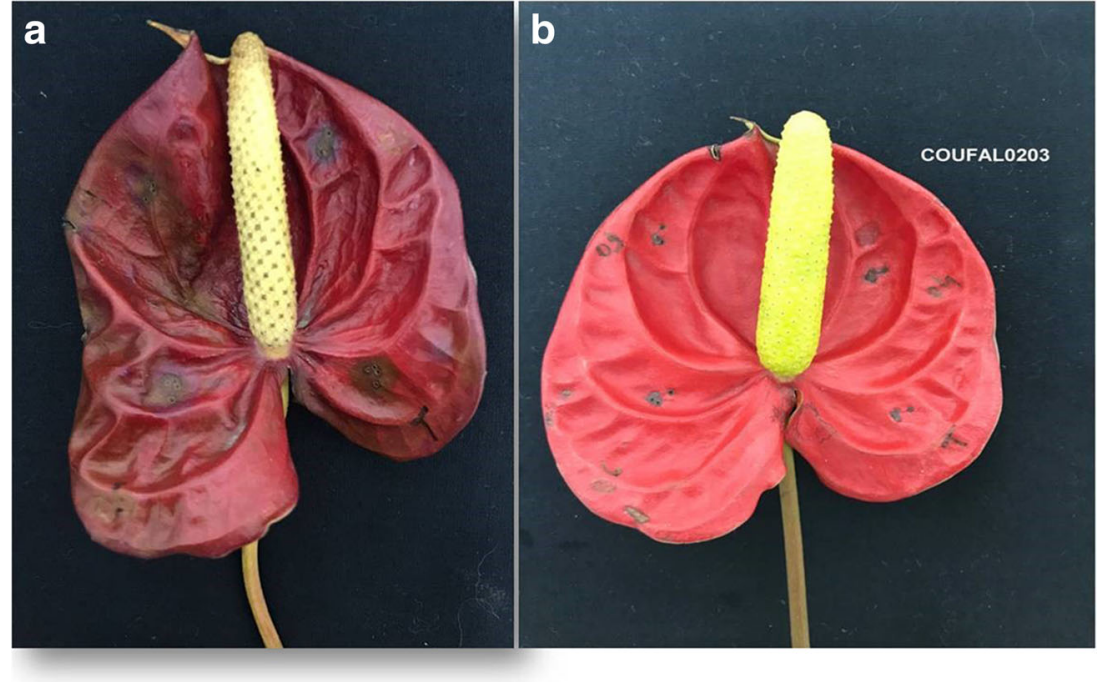

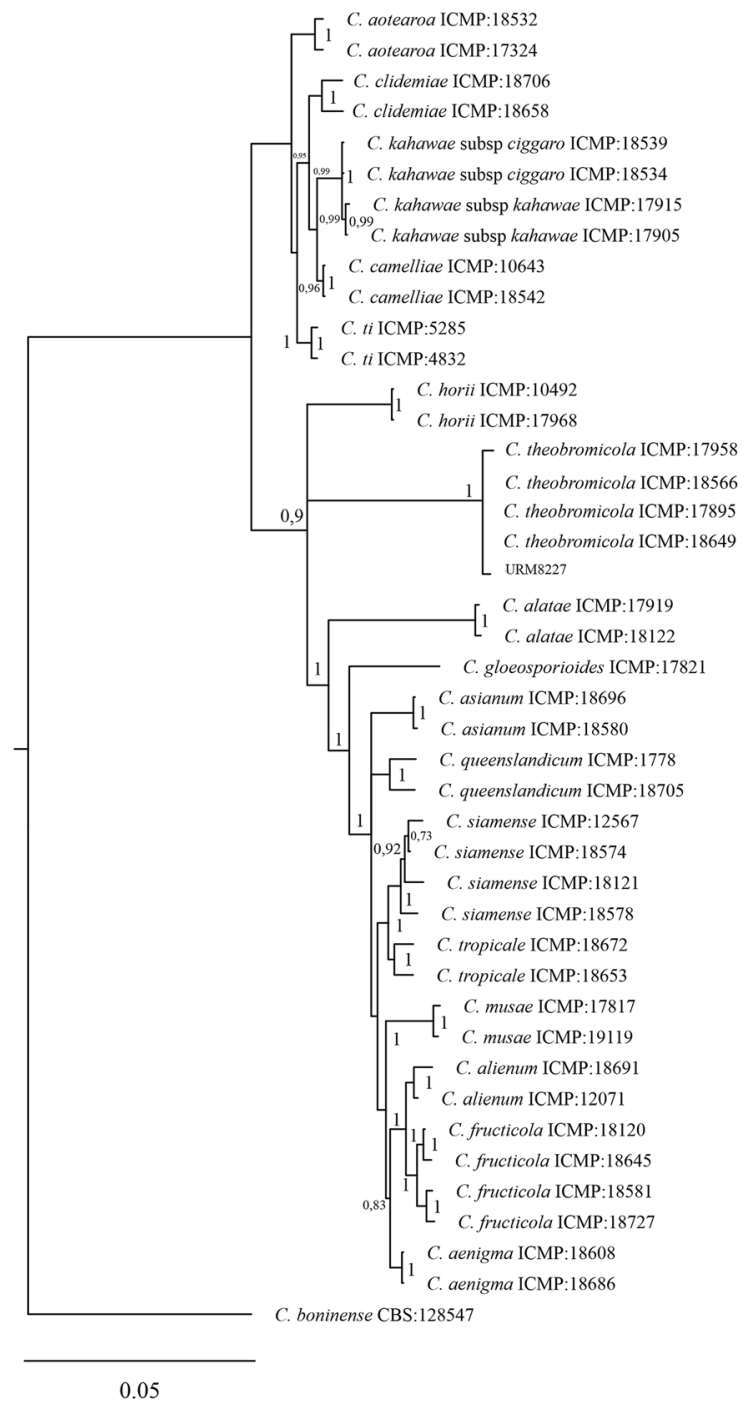

Fig. 2 Phylogenetic tree based on alignment of nucleotides sequences of genes ACT, CHS-1, CAL, GAPDH and ITS region using Bayesian analysis
MH155179, MH155176, MH155177 and MH155175 respectively). In addition, Bayesian inference analysis using concatenated sequences of genes (ITS, GAPDH, CAL, CHS, ACT) the Colletotrichum gloeosporioides species complex was performed. Based on Bayesian inference analysis and morphological characteristics, the URM8227 isolate obtained from diseased Anthurium flowers was identified as $C$. theobromicola (Rojas et al. 2010).

In order to confirm pathogenicity of $C$. theobromicola, healthy Anthurium flowers were first washed with distilled water following the protocol of Bellé et al. (2018). The flowers were inoculated with $10 \mu \mathrm{L}$ of conidial suspension $\left(10^{6}\right.$ spores $\left./ \mathrm{mL}\right)$ from a 7 -day-old culture (grown at $25{ }^{\circ} \mathrm{C}$ ) on PDA. Some of the Anthurium flowers were wounded with a sterile needle and others were not wounded. On control flowers, only sterilised water was used.

Inoculated flowers were kept in a humid chamber for 2 days at $25{ }^{\circ} \mathrm{C}$ with photoperiod of $12 \mathrm{~h}$. After 7 days, the flowers showed necrotic spot symptoms. No symptoms were observed on the control flowers. A culture of C. theobromicola was re-isolated from diseased flowers, thereby fulfilling Koch's postulates. Currently, The $C$. gloeosporioides species complex comprises more than 22 members, using multi locus phylogenetic analyses (Weir et al. 2012). However, in Brazil there are only reports of Colletotrichum gloeosporioides causing anthracnose in tropical flowers. (Warumby et al. 2004). Colletotrichum theobromicola was previously reported on Theobroma cacao, Coffea spp., Annona reticulata, A. muricata (Rojas et al. 2010; James et al. 2014; Udayanga et al. 2013) and in Brazil was first reported on eucalyptus (Rodrigues et al. 2014). To our knowledge, this is the first report of $C$. theobromicola causing anthracnose on flowers of Anthurium sp. in the world. 


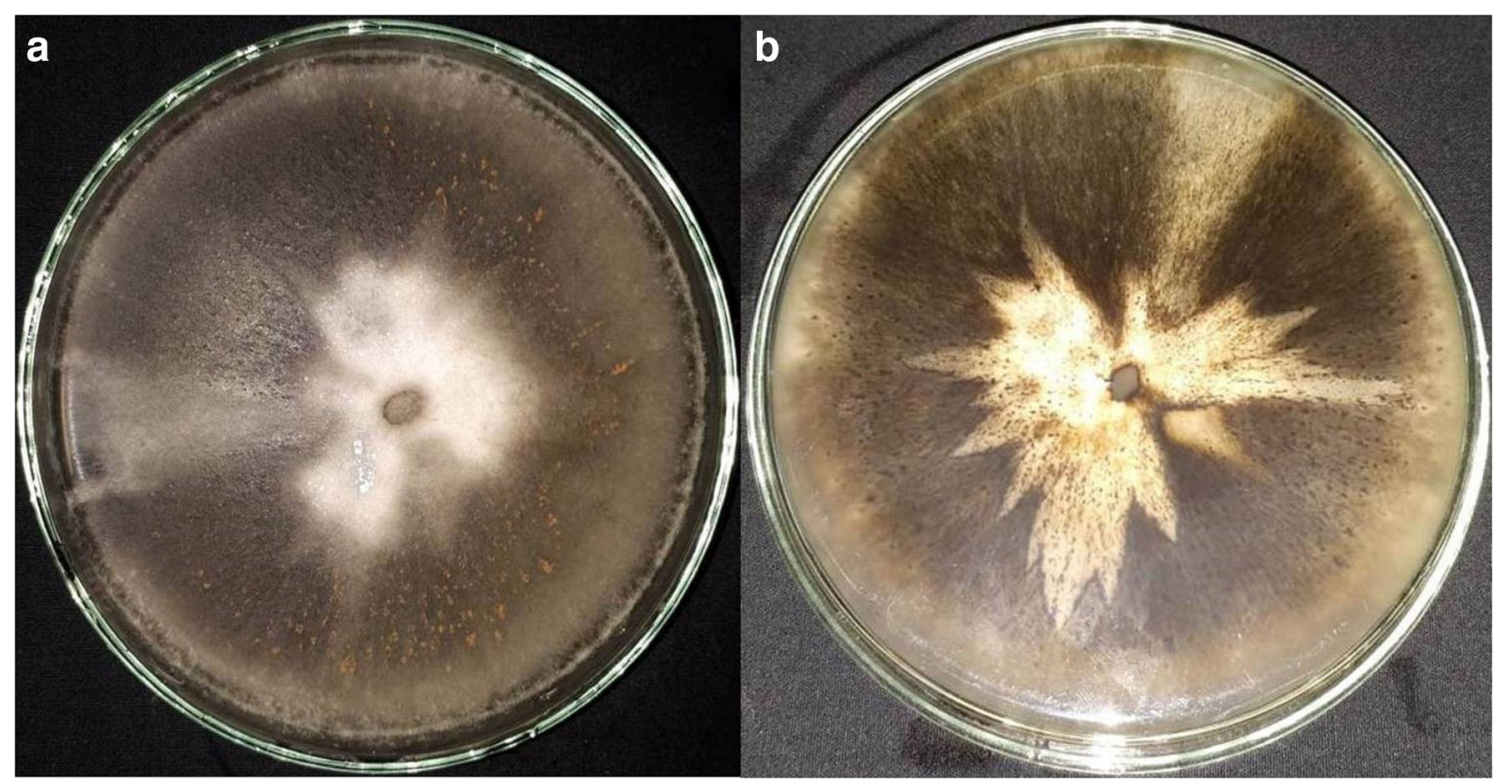

Fig. 3 Colony of Colletotrichum theobromicola on PDA 15-day-old (a) from above; (b) from below

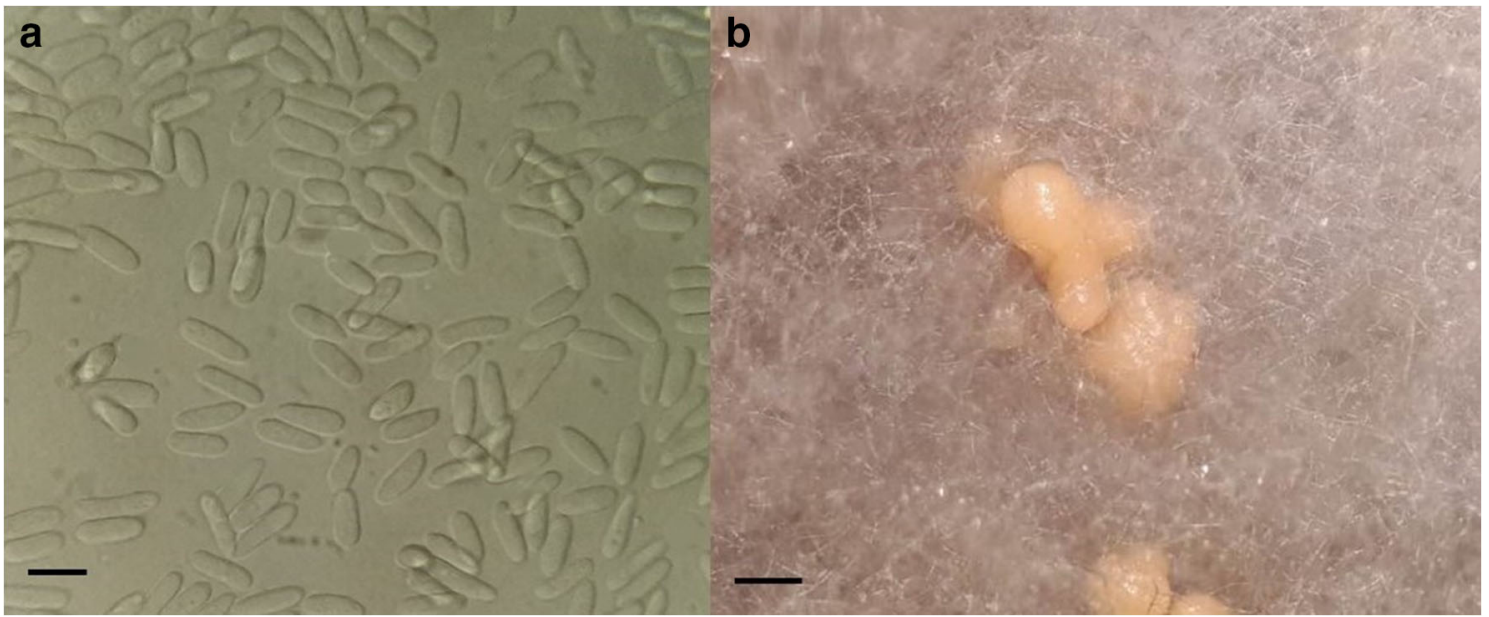

Fig. 4 (a) Conidia $(\times 100)$ of $C$. theobromicola; Scale bar $=15 \mu \mathrm{m}(\mathbf{b})$ conidiophores without setae on PDA 15-days-old; Scale bar $=0.5 \mathrm{~cm}$

\section{References}

Bellé C, Moccellin R, Souza-Júnior IT, Maich SLP, Neves CG, Nascimento MB, Barros DR (2018) First report of Colletotrichum acutatum causing flower anthracnose on pomegranate (Punica granatum) in southern Brazil. Plant Dis 102:2373. https://doi.org/ 10.1094/PDIS-04-18-0599-PDN

Carbone I, Kohn LM (1999) A method for designing primer sets for speciation studies in filamentous ascomycetes. Mycologia. 91: 553-556

James RS, Ray J, Tan YP, Shivas RG (2014) Colletotrichum siamense, C. theobromicola and $C$. queenslandicum from several plant species and the identification of $C$. asianum in the Northern Territory, Australia. Australasian Plant Disease Notes. https://doi.org/10. 1007/s13314-014-0138-x

Rodrigues AL, Pinho DB, Lisboa DO, Nascimento RJ, Pereira OL, Alfenas AC, Furtado GQ (2014) Colletotrichum theobromicola causes defoliation, stem girdling and death of mini-cuttings of Eucalyptus in Brazil. Tropical Plant Pathology. https://doi.org/10. 1590/S1982-56762014000400007
Rojas EI, Rehner SA, Samuels GJ, Van Bael SA, Herre EA, Cannon P, Chen R, Pang J, Wang R, Zhang Y, Peng YQ, Sha T (2010) Colletotrichum gloeosporioides s.1. associated with Theobroma cacao and other plants in Panamá: multilocus phylogenies distinguish host-associeted pathogens from asymptomatic endophytes. Mycologia. https://doi.org/10.3852/09-244

Sutton BC (1992) The genus Glomerella and its anamorph Colletotrichum. In: Bailey JA, Jeger MJ (eds) Colletotrichum: biology, Pathology and Control. CAB International, Wallingford, pp 1-26

Tombolato AFC, Castro ACR (2005) Araceae. In: Terao D, Carvalho ACPP, Barroso TCSF (eds) Flores tropicais. Embrapa Informações Tecnológicas, Brasília, p 225

Udayanga D, Manamgoda DS, Liu X, Chukeatirote E, Hyde KD (2013) What are the common antracnose pathogens of tropical fruits. Fungal Divers 61:165-179. https://doi.org/10.1007/s13225-0130257-2

Warumby JF, Coelho RSB, Lins SRO (2004) Principais doenças e pragas em flores tropicais no estado de Pernambuco. Sebrae, Recife

Weir BS, Johnston PR, Damm U (2012) The Colletotrichum gloeosporioides species complex. Stud Mycol 73:115-180. https:// doi.org/10.3114/sim0011 